\title{
MicroRNA microarray expression profiling in human myocardial infarction
}

\author{
Emanuela Boštjančič, Nina Zidar and Damjan Glavač* \\ Department of Molecular Genetics, Institute of Pathology, Faculty of Medicine, University of Ljubljana, Slovenia
}

\begin{abstract}
MicroRNAs (miRNAs), small non-coding RNA molecules, are negative regulators of gene expression. Recent studies have indicated their role in various forms of cardiovascular disease. In spite of the number of miRNA microarray analyses performed, little is known about the genome-wide miRNA expression pattern in human myocardial infarction (MI).

Using miRNA microarrays and bioinformatic analysis, miRNA expression was analyzed on human MI and foetal hearts compared to healthy adult hearts, to determine whether there is any similar expression pattern between MI and foetal hearts, and to identified miRNAs that have not previously been described as dysregulated in cardiovascular diseases.

Of 719 miRNAs analyzed, $\sim 50 \%$ were expressed in human hearts, 77 miRNAs were absent from all tested tissues and 57 were confidently dysregulated in at least one tested group. Some expression patterns appeared to be similar in MI and foetal hearts. Bioinformatic analysis revealed 10 miRNAs as dysregulated in MI not yet related to cardiovascular disease, and 5 miRNAs previously described only in animal models of cardiovascular diseases. Finally, qRT-PCR analysis confirmed dysregulation of 7 miRNAs, $m i R-150$, miR-186, miR-210, miR-451, and muscle-specific, miR-1 and miR-133a/b; all of these are believed to be involved in various physiological and pathological processes.
\end{abstract}

Keywords: MiRNA, microarray, myocardial infarction, expression

\section{Introduction}

MicroRNAs (miRNAs) comprise a novel class of endogenous, small non-coding RNAs that negatively regulate gene expression. By means of post-transcriptional targeting of mRNA, they cause translational inhibition or degradation of their targets [1]. It has been predicted that they constitute more than $3 \%$ of human genes, regulating $\sim 30 \%$ of protein-coding genes [2]. It has been established that they represent developmental expression patterns, important for timing developmental decisions [3], pattern formation [4] and tissue-specific expression patterns [5]. They have been implicated in the regulation of insulin secretion, resistance to viral infection and genomic rearrangements associated with genetic disorders and cancer [6].

* Corresponding author: Damjan Glavač, $\mathrm{PhD}$, Department of Molecular Genetics, Institute of Pathology, Korytkova 2, Faculty of Medicine, University of Ljubljana, 1000 Ljubljana, Slovenia. Tel.: +386 1543 7180; Fax: +386 1543 7181; E-mail: damjan.glavac@ mf.uni-lj.si.
In addition, they are believed to be key regulators in cardiovascular biology, although the majority of studies have been concerned with development, conduction and pathology, focusing on hypertrophy, end-stage heart failure, dilated and ischemic cardiomyopathy, and aortic stenosis $[1,2,7,8]$. Certain cardiac diseases, including those with progressive degeneration, might involve abnormal miRNA regulation leading to loss of renewal of cardiac muscle cells. Stress, long associated with cardiac diseases, has profound effects on miRNA patterns in the heart, suggesting that miRNAs might function in stress-related factors to affect cardiac structure and function [6].

Previous studies of cardiac disease have focused on miRNAs that are primarily expressed in cardiomyocytes [8]. However, there is mounting evidence that other miRNAs expressed in human heart have an impact on cardiovascular disease $[1,2,7,8]$. In several studies, miRNA microarray analysis has been performed using cell lines and an animal model of hypertrophy [9-12], human cardiomyopathies and aortic stenosis [13,14], 
end-stage heart failure $[15,16]$, a dicer deletion animal model [17], fibrosis [18], an animal model of myocardial infarction (MI) [19,20], development [21] and an animal model of remodelling and reverse remodelling of the heart [22] but, to the best of our knowledge, genome-wide miRNA expression profiling on $\mathrm{MI}$ in humans has not been previously reported.

Our study thus focused on miRNA expression analysis in MI and foetal hearts compared to healthy adult hearts, in order to identify miRNAs that could be potentially dysregulated in response to cardiac ischemia, and to identify any similar expression patterns in foetal and infarcted tissue.

\section{Materials and methods}

\subsection{Patients and tissue samples}

Our study included autopsy samples of infarcted heart tissue and border zone from 39 patients with MI. MI was diagnosed clinically by symptoms and/or electrocardiographic changes, and confirmed by elevated plasma levels of markers of cardiac necrosis. Autopsies were performed within 24 hours after death. Tissue samples were fixed in $10 \%$ buffered formalin and embedded in paraffin. The duration of MI at the time of death was estimated on the basis of histological changes and clinical data, and all cases of MI were divided into two groups - up to 7 days old infarcted tissue and more than 4 weeks old infarcted tissue. Of 39 patients, 24 were males and 15 females, aged 57-94 years. Diabetes and arterial hypertension were recorded in 8 and 26 patients, respectively. Fifteen patients had received reperfusion treatment.

The control group consisted of autopsy heart tissue from 11 healthy adults who had died in accidents and 14 foetal hearts at gestation ages of 23 to 40 weeks that had died in uterus. Post mortem delay did not exceed 24 hours, and there was no macroscopical or microscopical evidence of disease at autopsy.

The investigation conformed to the principles outlined in the Helsinki Declaration. The Ethics Review Board of the National Medical Ethics Committee (NMEC) of the Republic of Slovenia granted approval for this research (approval reference number: 39/01/08).

\subsection{RNA isolation}

Tissue samples were cut at $10 \mu \mathrm{m}$ from formalinfixed paraffin-embedded tissue blocks using a microtome. Six to eight $10-\mu \mathrm{m}$ sections were used for the isolation procedure. Total RNA isolation was performed using a miRNeasy FFPE kit (Qiagen) according to the manufacturer's protocol. All the reagents were from Qiagen, except where otherwise indicated. Briefly, $1 \mathrm{ml}$ of Xylene (Merck) was added for deparaffinisation, followed by brief vortexing and centrifugation. After the ethanol-washing step, the pellets were air-dried and digestion with Proteinase $\mathrm{K}$ was performed at $55^{\circ} \mathrm{C}$ for $15 \mathrm{~min}$, followed by $15 \mathrm{~min}$ incubation at $80^{\circ} \mathrm{C}$ in order partially to reverse formaldehyde modification of the nucleic acid. After the gDNA elimination step, $100 \%$ ethanol (Merck) was added to the samples and the mixture was transferred to an RNeasy MinElute spin column. After two washing steps, the RNA was eluted in $30 \mu \mathrm{l}$ of nuclease-free water.

The concentration of RNA extracted was measured using a NanoDrop-1000 (Thermo Scientific) and tested for UV/vis ratios. The $\mathrm{A}_{260} / \mathrm{A}_{230} \mathrm{~nm}$ intensity ratio needs to be above 1.0 and $\mathrm{A}_{260} / \mathrm{A}_{280}$ ratio needs to be above 1.8. The integrity and presence of small RNAs $(<200$ nucleotides) was analyzed on a Bioanalyzer 2100 (Agilent, USA), which is a microfluidicsbased platform. The Small RNA Assay and Bioanalyzer 2100 allow miRNA to be separated, verified and optimized after extraction procedures. After applying $1 \mu \mathrm{l}$ of sample to the high resolution Small RNA Assay and using the SmallRNA Ladder as reference, we obtained a detailed view of the RNA of 6-150 nt in range and looked for the presence of $\sim 22 \mathrm{nt}$ long RNA molecules.

\section{3. microRNA microarray analysis}

Expression analysis was performed using hybridization to $\mu$ Paraflo ${ }^{\circledR}$ microfluidics micorarrays (LC Sciences) in the version of the Sanger miRBase database Release 10.1. Each of the microarrays held all 719 predicted mature human miRNA probes (MRA-1001, the latest version of the Sanger miRBase database at the time of analysis, with $100 \%$ of experimentally verified miRNA sequences represented on the arrays), as well as spike-in/perfectly matched and mismatched probes for quality control. Each detection probe consisted of a chemically modified nucleotide-coding segment complementary to the target miRNA or other target and a spacer segment of polyethylene glycol to extend the 
coding segment away from the substrate. Each miRNA probe was represented 5 times on a single microarray, and the control probes were spiked into the RNA samples before labelling. The detection probes were made by in situ synthesis using PGR (photogenerated) chemistry, which enables highly sensitive and specific direct detection of miRNAs. The $\mu$ Paraflo ${ }^{\circledR}$ technology enables on-chip synthesis, ensuring high probe quality and tight process control.

\subsubsection{Microaray design}

Five to ten $\mu \mathrm{g}$ of RNA from heart samples was used for the miRNA microarrays (LC Sciences). Using sizefractionation (YM-100 Microcon centrifugal filter, Millipore), small RNA ( $<300 \mathrm{nt})$ enrichment was performed, following a 3 '-extension with a poly(A) tail using poly(A) polymerase, to which an oligonucleotide tag was added for subsequent labelling. The use of a proprietary labelling method utilizes an affinity tag for signal amplification after miRNA hybridization to the microarrays. The microarray experiments were performed as dual-sample experiments, using dual colour labelling (Cy3 and $\mathrm{Cy} 5$ fluorescent dyes) and also a colour reversal approach. In the case of the dual-sample experiment, the two sets of RNA sequences were labelled with two different affinity tags to allow simultaneous detection of both samples. The two samples were then hybridized to a single Atactic $\mu$ ParaFlo microfluidic chip. Hybridization was performed overnight on a $\mu$ ParaFlo microfluidic chip, using a microcirculation pump (Atactic Technologies). The hybridization melting temperatures were balanced by chemical modifications of the detection probes. Hybridization used 6xSSPE buffer $\left(0.90 \mathrm{M} \mathrm{NaCl}, 60 \mathrm{mM} \mathrm{Na}_{2} \mathrm{HPO}_{4}, 6 \mathrm{mM}\right.$ EDTA, pH 6.8) containing $25 \%$ formamide at $34^{\circ} \mathrm{C}$. After RNA hybridization, tag-conjugating $\mathrm{Cy} 3$ and $\mathrm{Cy} 5$ dyes were circulated through the microfluidic chip for dye staining. Fluorescence images were collected by using a laser scanner (GenePix4000B; Molecular Devices) and digitized by using Array-Pro image analysis software (Media Cybernetics).

Nine microRNA microarrays were performed, using RNA samples from 3 foetal hearts and 6 infarcted tissues (up to 7 days and more than 4 weeks old) and compared to 6 healthy adult hearts.

\subsubsection{Microarray analysis}

Standard data analysis was performed to detect small amounts of miRNA, including calculation of signal intensities, determination of detectable transcripts and calculation of differential ratios. The signal was amplified and the determined background was subtracted using the local regression method. Cy3/Cy5 channel normalization was carried out using a cyclic LOWESS (locally-weighted regression) method. These transcripts were defined as "processed data". In addition, detectivity determination was based on the following conditions: (i) signals of the repeating probes should be above the detection level in at least 3 of 5 probes for each miRNA, (ii) signal intensity should be higher than $3 \mathrm{x}$ background standard deviation, (iii) spot CV should be less than 0.5. Transcripts meeting those conditions were determined as "simple detectable or detectable transcripts".

For the dual colour experiment, the differences between $\mathrm{Cy} 3$ and $\mathrm{Cy} 5$ signals and p-values of the differences were calculated. When the p-value was less than 0.01 , the differentially detected signals were considered to be true and used for data filtering. miRNAs with intensity values below a threshold value were removed; in addition, $\log _{2}$ transformation was used to convert expression values into a linear scale $\left(\log _{2}\right)$ for statistical comparison.

\subsection{Quantitative real-time PCR ( $q R T-P C R)$}

Some miRNAs that appeared to be differently expressed in miRNA microarray expression analysis were validated using a miScript system (Qiagen) based on Sybr Green technology and/or TaqMan-based miRNA quantification. All the reagents were from the Qiagen for miScript system or from the Applied Biosystems for TaqMan based approach, except where otherwise indicated. qRT-PCR was carried out using the Applied Biosystems 7900 Real-Time PCR System.

\subsubsection{DNA digestion step}

RNA obtained from FFPE heart tissue samples was first treated with DNAse I prior to qRT-PCR to eliminate the possibility of non-specific detection of doublestranded DNA amplified during the qRT-PCR reaction. Up to $1 \mu \mathrm{g}(5 \mu \mathrm{l})$ of RNA contaminated with genomic DNA was used, treated with a mix containing $2 \mu 110 \mathrm{x}$ DNase buffer (RDD buffer), 10 units RNase inhibitor, 0.5 Kunitz units DNase I and filled with RNase-free water to obtain a $20 \mu \mathrm{l}$ reaction mixture. After a $30 \mathrm{~min}$ incubation step at $37^{\circ} \mathrm{C}, 2 \mu \mathrm{l} 140 \mathrm{mM}$ EDTA (Sigma) was added to the reaction and incubated for $5 \mathrm{~min}$ at $65^{\circ} \mathrm{C}$ to inactivate DNase I. The concentration was measured using NanoDrop-1000. 


\subsubsection{No-reverse transcriptase control}

This step included all the qRT-PCR reagents with the primer controls and the RNA treated with DNAase I, without the reverse transcription step. If the product was amplified, it indicated that there was still some genomic DNA contamination.

\subsubsection{Reverse transcription and $q R T-P C R$ using miScript system}

A miScript reverse transcription kit was used for reverse transcription. Briefly, a 15- $\mu$ l reaction master mix was created, containing $100 \mathrm{ng}$ of total RNA, $3 \mu \mathrm{l}$ 5x miScript RT buffer, $0.75 \mu \mathrm{l}$ miScript reverse transcriptase mix and 10 units $(0.33 \mu \mathrm{l})$ RNase inhibitor. After incubation for $60 \mathrm{~min}$ at $37^{\circ} \mathrm{C}$ and $5 \mathrm{~min}$ at $95^{\circ} \mathrm{C}$, the cDNA was diluted 10-fold, and $4.5 \mu \mathrm{l}$ was used for each qRT-PCR reaction. The $15 \mu \mathrm{l}$ PCR master mix contained $7.5 \mu 12 x$ QuantiTect SYBR Green PCR Master Mix, $1.5 \mu \mathrm{l}$ miScript universal primer and $1.5 \mu \mathrm{l}$ 10x miScript Primer Assay. RNU6B was used as the internal control gene, according to the manufacturer's protocol. All the qRT-PCR reactions were performed in duplicate or triplicate. The signal was collected at the endpoint of every cycle. Following amplification, melting curves analysis of PCR products was performed to verify specify and identity. Melting curves were acquired on the SYBR channel using a ramping rate of $1{ }^{\circ} \mathrm{C} / 60 \mathrm{~s}$ for $60-95^{\circ} \mathrm{C}$.

\subsection{4. $M i R N A$ reverse transcription and \\ TaqMan-based qRT-PCR analysis}

Looped primers for specific miRNA reverse transcription, including $h s a-m i R-1, h s a-m i R-133 a$ and $h s a-$ $m i R-133 b$ and internal control gene $R N U 48$, were utilized following the manufacturer's protocol. All reagents and instruments were from Applied Biosystems, except where otherwise indicated. Briefly, the $15 \mu \mathrm{l}$ reverse transcription (RT) reaction master mix was performed with $10 \mathrm{ng}$ of total RNA sample. qRTPCR was carried out using the Applied Biosystems 7900 Real-Time PCR System in $20 \mu$ PCR master mix containing $10 \mu \mathrm{l}$ TaqMan 2x Universal PCR Master Mix, $1 \mu \mathrm{l}$ TaqMan assay, $9 \mu \mathrm{l}$ RT products diluted 10fold. The qRT-PCR reactions were performed in triplicate and the signal was collected at the endpoint of every cycle.

\subsection{Statistical and bioinformatic analysis}

\subsubsection{Statistical analysis of microarrays}

We performed microarray analysis using processed data (background subtracted, normalized) and the Acuity 4.0 program to define: (i) which miRNAs are differently expressed in infarcted tissue (up to 7 days and more than 4 weeks old) or foetal hearts, when compared to healthy adult hearts; (ii) if there is any similar expression pattern in human MI when compared to foetuses. To test differential miRNA expression between foetal and infarcted tissue (up to 7 days and more than 4 weeks old), ANOVA and the Mann-Whitney test were performed between separate groups $(p \leqslant 0.01$ and $p \leqslant$ 0.05 , FDR corrected using the Benjamini-Hochberg correction [23]).

Statistical analysis was further performed using the Mann-Whitney test (FDR corrected $p \leqslant 0.01$ and $p \leqslant$ 0.05 using the Benjamini-Hochberg correction) and cross tested as follows: (i) up to 7-day old MI and foetuses versus more than 4-week old MI; (ii) all MI versus foetuses; (iii) up to 7-day old MI versus foetuses and more than 4-week old MI.

To identify miRNA as dysregulated, it should meet either of two conditions: first, the $\log _{2}$ ratio should be $\geqslant 2$-fold; second, statistical analysis should identify it as being significantly dysregulated between groups. Finally, an miRNA expression heat map was constructed by unsupervised hierarchical clustering to reveal the relationship of each microarray to every other microarray, without prior knowledge of how the data would cluster.

\subsubsection{Bioinformatic analysis of microarrays}

Bioinformatic analysis of dysregulated miRNAs identified by microarray analysis included searching for these miRNAs in (i) PubMed publications relating to cardiovascular diseases or any other publication (ii) miRBase - if they have been further treated as miRNA or subsequently removed from the database [24]; (iii) HMDD (Human MicroRNA Disease Database) [25] to discover whether they are related to cardiovascular diseases.

In addition, we performed microarray analysis using received data defined as "detectable transcripts" in order to define the percentage of expressed miRNAs in each group of tested samples, including foetal hearts, up to 7-day old MI, more than 4-week old MI and healthy adult hearts. The aim of this analysis was to identify miRNAs that were expressed in heart tissue but showed no differential expression between tested groups, or miRNAs that were absent from all 15 tested samples. 


\subsubsection{Target prediction}

TargetScan5.1 and miRanda programs [26] were used to search targets for dysregulated miRNAs. Furthermore, defined genes were subjected to search across PubMed to define whether they may have a potential function in cardiovascular pathology, and subjected to the above programmes to define the number of potential binding sites and their conservation across species. In addition, Gene Functional Classification of the defined genes using the DAVID program was performed [27].

\subsubsection{Statistical analysis of $q R T-P C R$ results}

The $2^{-\Delta \Delta C t}$ method was used to present the relative gene expression obtained from qRT-PCR analysis, whereby the fold changes of the tested groups were calculated relative to the calibrator group. The calculated $\Delta \mathrm{Ct}$ in different groups (MI up to 7 days old, and foetal hearts) were compared to the $\Delta \mathrm{Ct}$ of the control group (healthy adult hearts) and tested for statistical significance using the Mann-Whitney test for independent groups of samples, with a cut off point at $p<0.05$. SPSS analytical software ver.16, SPSS Inc. IL, was used. If the $\Delta \mathrm{Ct}$ of the tested groups was significantly higher or lower than the $\Delta \mathrm{Ct}$ of the control group, the expression change was considered to be statistically significant.

\section{Results}

\subsection{MiRNA microarray results}

\subsubsection{Statistical analysis of microarrays}

MicroRNA microarray expression analysis using hybridization to $\mu$ Paraflo ${ }^{\circledR}$ microfluidics microarrays (LC Sciences), which held 719 miRNAs (Sanger miRBase database Release 10.1.) revealed that there were 93 differentially expressed miRNAs, of which 47 were differentially expressed in MI up to 7 days old, $30 \mathrm{miR}$ NAs in MI more than 4 weeks old, and 74 in foetal hearts when compared to healthy adult hearts. Only 13 of the 93 differentially expressed miRNAs showed upor down-regulation in all tested groups (Fig. 1).

In searching for similar expression patterns in foetal hearts and MI, we first performed ANOVA and the Mann-Whitney test using Acuity 4.0 analytical software. Of 93 miRNAs that were differentially expressed, 57 were treated as dysregulated, either showing a $\log _{2}$ ratio $\geqslant 2$ or achieving statistically significant dysregulation between the groups (Table 1).

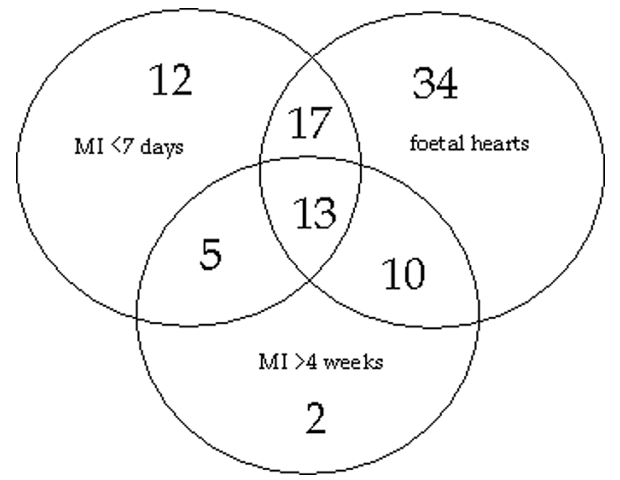

Fig. 1. Differentially expressed miRNAs among tested groups. Numbers represent the number of miRNAs differentially expressed in a tested group or overlapping between groups. Legend: MI $<7$ days, myocardial infarction less than 7 days old; $\mathrm{MI}>4$ weeks, myocardial infarction more than 4 weeks old.

Unsupervised hierarchical clustering was performed using (i) all 196 miRNAs differentially expressed in at least one microarray, (ii) 13 miRNAs that were dysregulated in all 9 microarrays, (iii) miRNAs differentially expressed in MI up to 7 days old and foetuses (iv) miRNAs differentially expressed in MI up to 7 days and more than 4 weeks old, (v) miRNAs differentially expressed in foetuses and MI more than 4 weeks old. All of the expression heat maps defined some similar expression patterns in MI more than 4 weeks old and foetal hearts (Fig. 2).

\subsubsection{Bioinformatic analysis of microarrays}

Because the aim of our study included identification of some novel miRNAs, a search across PubMed publications, HMDD and miRBase was performed. miRBase revealed that human mir-923 appears to be a fragment of 28S rRNA, so has been removed from the miRBsae database. miR-768 overlaps an annotated snoRNA, HBII-239; phylogenetic analysis in all vertebrates supports the snoRNA annotation, with poor conservation of the reported mature miRNA sequence; it has therefore been removed from the database. Of 10 miRNAs defined as dysregulated in our study, 9 have no record in HMDD and 8 have no record in PubMed, and none of the 10 miRNAs have been previously described in the setting of cardiovascular diseases. To the best of our knowledge, therefore, the following 10 miRNAs, hsa-miR-1231, hsa-miR-193a-5p, hsa-miR-572, hsamiR-574-3p, hsa-miR-575, hsa-miR-671-5p, hsa-miR933, hsa-miR-940 and hsa-miR-149*, hsa-miR-29c*, have not been previously described in the setting of cardiovascular diseases (Table 1). Furthermore, 5 miRNAs, hsa-miR-25, hsa-miR-503, hsa-miR-574-5p and 
Table 1

MiRNAs defined as dysregulated in miRNA microarray analysis

\begin{tabular}{|c|c|c|c|c|c|c|}
\hline \multirow[t]{2}{*}{ miRNA } & \multicolumn{4}{|c|}{$\log _{2}$ ratio } & \multicolumn{2}{|c|}{$\begin{array}{l}\text { Previously described miRNAs in cardiovascular diseases } \\
\text { using miRNA microarray expression profiling (references) }\end{array}$} \\
\hline & $\begin{array}{r}<7 \text { days } \\
\text { old MI }\end{array}$ & $\begin{array}{r}>4 \text { weeks } \\
\text { old MI }\end{array}$ & $\begin{array}{l}\text { Foetal } \\
\text { hearts }\end{array}$ & p-value & Human samples & $\begin{array}{l}\text { Animal models } \\
\text { and cell lines }\end{array}$ \\
\hline hsa-let-7a & -1.04 & 0.49 & 0.91 & $*$ & $\mathbf{1 3}, 14,15,16$ & $\mathbf{1 1}, 19,22$ \\
\hline hsa-let-7b & -0.32 & 0.87 & & & 14,15 & $\mathbf{1 0}, 17, \mathbf{1 8}, 22$ \\
\hline hsa-let-7c & -0.88 & 0.88 & 0.85 & * & $\mathbf{1 3}, 14,15$ & $10, \mathbf{1 1}, 19,22$ \\
\hline hsa-let-7d & -1.33 & 0.64 & 1.25 & $*$ & $\mathbf{1 3}, 14,15,16$ & $11,18,22$ \\
\hline hsa-let-7e & -1.82 & & 1.44 & $*$ & $14,15,16$ & $11,18,22$ \\
\hline hsa-let-7f & -1.41 & & 0.64 & * & $\mathbf{1 3}, 14,15,16$ & 11 \\
\hline hsa-let-7g & -1.67 & & & & 14,16 & 11,18 \\
\hline hsa-let-7i & & & 0.91 & & 16 & 11 \\
\hline hsa-miR-1 & -1.89 & -1.66 & -0.59 & & $\mathbf{1 3}, 14,15,16$ & $10,17,21$ \\
\hline hsa-miR-103 & & & 1.10 & & 14 & $10,11,17,18,21$ \\
\hline hsa-miR-106a & & & 2.91 & & $12,14,16,20$ & 17,18 \\
\hline hsa-miR-106b & & & 2.07 & & $14,15,16$ & $10,18,21$ \\
\hline hsa-miR-107 & & & 1.19 & & $14,15,16$ & $\mathbf{1 0}, 17, \mathbf{1 8}$ \\
\hline hsa-miR-1231 & 4.32 & & & $*$ & This study & \\
\hline hsa-miR-125a-5p & -1.46 & & 0.50 & & 15,16 & $11,17,22$ \\
\hline hsa-miR-125b & -0.47 & & -0.39 & & $12, \mathbf{1 3}, 14,16$ & $9, \mathbf{1 0}, \mathbf{1 1}, 22$ \\
\hline hsa-miR-126 & -0.50 & -0.68 & -0.94 & & $14,15,16$ & $11,17,18,21$ \\
\hline hsa-miR-128 & & & 1.20 & & 15 & 18 \\
\hline hsa-miR-130a & & & 3.17 & & $14,15,16$ & 18,22 \\
\hline hsa-miR-130b & & & 3.13 & & 15 & 19,22 \\
\hline hsa-miR-132 & & 2.93 & 2.02 & & 15 & 18 \\
\hline hsa-miR-133a & & -0.45 & -0.94 & & $12, \mathbf{1 3}, 14,16$ & $9, \mathbf{1 1}, 17, \mathbf{2 1}$ \\
\hline hsa-miR-133b & & -0.48 & -1.02 & & $\mathbf{1 3}, 14,16$ & $9, \mathbf{1 1}, 17,19,21$ \\
\hline hsa-miR-139-5p & -2.11 & & & & 13 & 10,18 \\
\hline hsa-miR-143 & & -0.84 & & & 14,16 & $\mathbf{1 1}, 17, \mathbf{1 8}, \mathbf{2 1}, 22$ \\
\hline hsa-miR-145 & & 0.23 & 0.18 & & 14,16 & $\mathbf{1 1}, 17$ \\
\hline hsa-miR-149* & 4.62 & & -3.58 & $*$ & This study & \\
\hline hsa-miR-150 & 1.60 & & -2.01 & & $12, \mathbf{1 3}, 14,15,20$ & $9, \mathbf{1 0}, \mathbf{1 1}, \mathbf{1 8}$ \\
\hline hsa-miR-151-5p & -0.96 & & 1.02 & * & 16 & $10,21,22$ \\
\hline hsa-miR-152 & -1.73 & & & & 14,16 & 11 \\
\hline hsa-miR-15b & -1.45 & & 5.10 & $*$ & 14 & 10,18 \\
\hline hsa-miR-16 & & & 1.98 & & $14,15,16$ & 11,18 \\
\hline hsa-miR-17 & & & 2.89 & & $12,14,15,16,20$ & 18 \\
\hline hsa-miR-181a & & & 1.26 & & 14,16 & 11 \\
\hline hsa-miR-181b & & & 2.72 & ** & 13 & 9 \\
\hline hsa-miR-185 & & -1.02 & -1.65 & & 14,16 & $10,11,18,22$ \\
\hline hsa-miR-186 & 2.33 & & & & 15 & \\
\hline hsa-miR-191 & & & 1.23 & $*$ & 14,16 & 11 \\
\hline hsa-miR-193a-5p & & & -1.78 & & This study & \\
\hline hsa-miR-195 & -1.37 & 1.46 & & & $\mathbf{1 3}, 14,16$ & $9, \mathbf{1 0}, \mathbf{1 1}, 17$ \\
\hline hsa-miR-197 & & & 1.16 & & 13 & \\
\hline hsa-miR-199a-3p & & 0.99 & 2.64 & & $\mathbf{1 3}, 15,16,20$ & $\mathbf{1 0}, 17, \mathbf{1 8}$ \\
\hline hsa-miR-20a & & & 2.71 & & $\mathbf{1 3}, 14,16$ & 18 \\
\hline hsa-miR-20b & & & 3.31 & & $12,14,20$ & $\mathbf{1 8}, 19,20$ \\
\hline hsa-miR-21 & & & 3.48 & & $12,14,15,16$ & $9, \mathbf{1 0}, \mathbf{1 1}, 17, \mathbf{1 8}, 19$ \\
\hline hsa-miR-210 & 1.78 & -1.66 & & & 12,15 & 19,21 \\
\hline hsa-miR-214 & 0.58 & 1.53 & 2.50 & & 14,16 & $\mathbf{1 0}, \mathbf{1 1}, 17, \mathbf{1 8}, 22$ \\
\hline hsa-miR-22 & & & -4.42 & $* *$ & 13, $14,15,16$ & $11,17,18$ \\
\hline hsa-miR-22* & -2.27 & & & & & 18 \\
\hline hsa-miR-221 & & -1.46 & -3.10 & $*$ & $12, \mathbf{1 3}, 16,20$ & $10,18,20$ \\
\hline hsa-miR-222 & & & -2.55 & & $12, \mathbf{1 3}, 14,16,20$ & 10,18 \\
\hline hsa-miR-23a & -0.20 & 1.45 & 0.91 & & $12, \mathbf{1 3}, 14,16$ & $\mathbf{9}, \mathbf{1 0}, 22$ \\
\hline hsa-miR-23b & -0.14 & & 0.57 & $*$ & $14,15,16$ & $9, \mathbf{1 0}, \mathbf{1 1}, 22$ \\
\hline hsa-miR-24 & & 0.32 & -0.76 & & $14,15,16$ & $9, \mathbf{1 0}, 11$ \\
\hline hsa-miR-25 & & & 2.70 & $* *$ & & 9 \\
\hline hsa-miR-26a & -0.54 & & 0.83 & & $14,15,16$ & $\mathbf{1 0}, \mathbf{1 1}, 19,22$ \\
\hline hsa-miR-26b & -2.69 & & 1.64 & & 13, 14,16 & $10,11,18$ \\
\hline
\end{tabular}


Table 1, continued

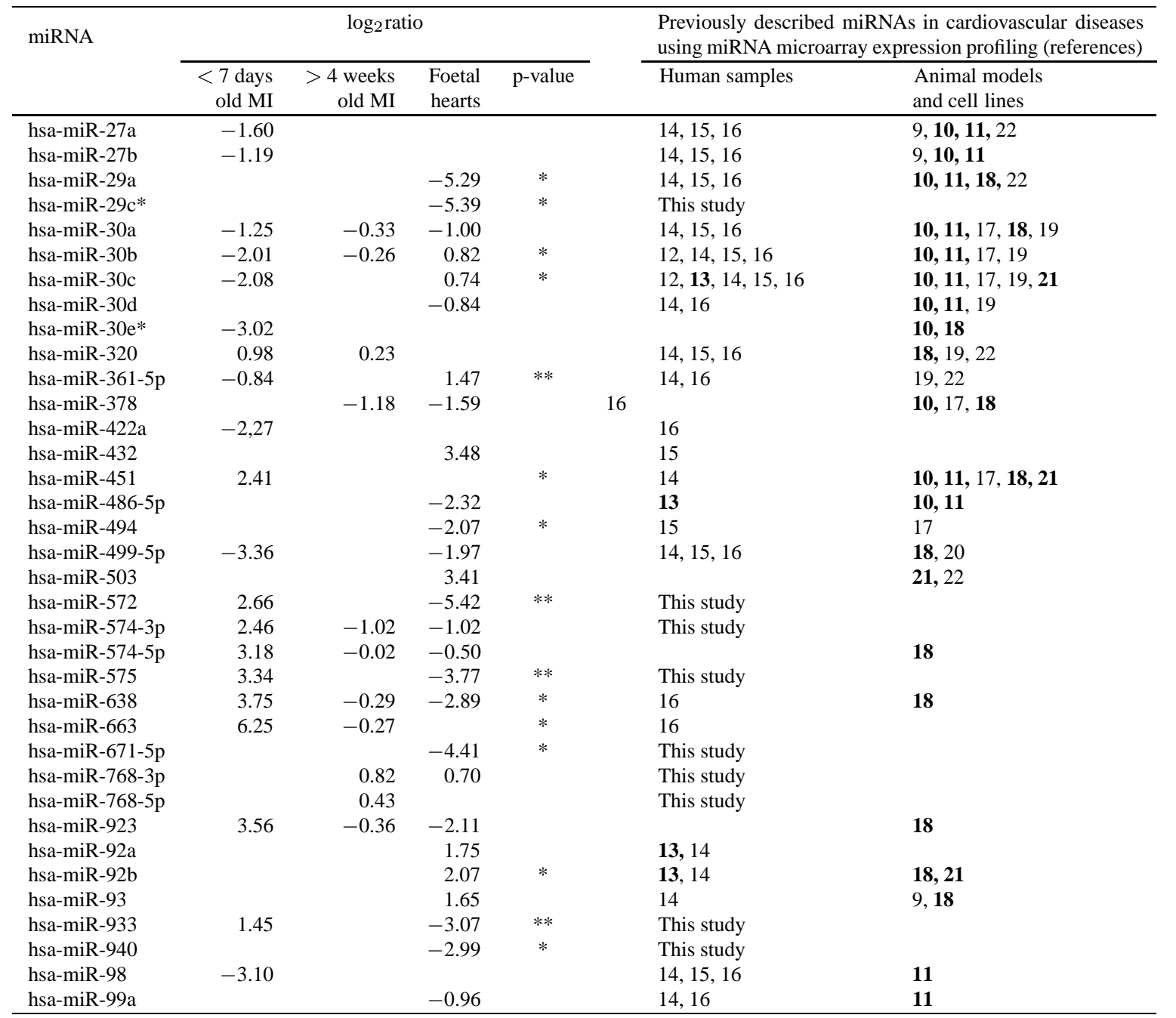

Missing $\log _{2}$ ratio data show undetected or not uniformly detected miRNAs in a tested group. miRNAs were treated as confidently dysregulated if they showed either a $\log _{2}$ ratio $\geqslant 2$ or reached statistically significant dysregulation between groups. An asterisk represents a $\log _{2}$ ratio that reached FDR corrected statistical significance using either ANOVA or the Mann-Whitney test between groups (one asterisk, $p<0.05$; two asterisks, $p<0.01$ ). Bold face reference numbers represent analysis of miRNA microarrays using LC Sciences technology.

$h s a-m i R-22 *, h s a-m i R-30 e^{*}$, are believed to be identified for the first time as dysregulated in diseased heart in humans (Table 1). Further analysis identified 17 miRNAs that were detected only by the latest update with the Sangre miRBase database (Table 1).

Our further analysis, using data defined as detectable transcripts, identified 101 miRNAs that were detected in all 15 tested heart tissues, and 77 miRNAs that were below the detection signals in all microarrays (Table 2). Among miRNAs detected in all tested tissues, 53 appeared to be differentially expressed between tested groups (Tables 1 and 2). Finally, to obtain the number of miRNAs detected in heart tissue, the frequen- cies of miRNAs expressed across tested samples from MI, foetal hearts and healthy adult hearts were calculated. These miRNAs were defined as detectable across samples, but had either similar signal intensity or were absent from other microarrays and were therefore not treated as dysregulated (Fig. 3).

\subsubsection{Target prediction}

Using different approaches (TargetScan5.1, miRanda), we predicted in silico a list of potential target genes for 5 miRNAs, which are believed to be reported for the first time as dysregulated in human MI. These miRNAs are $m i R-572, m i R-574-3 p$, miR-933, miR-1231 


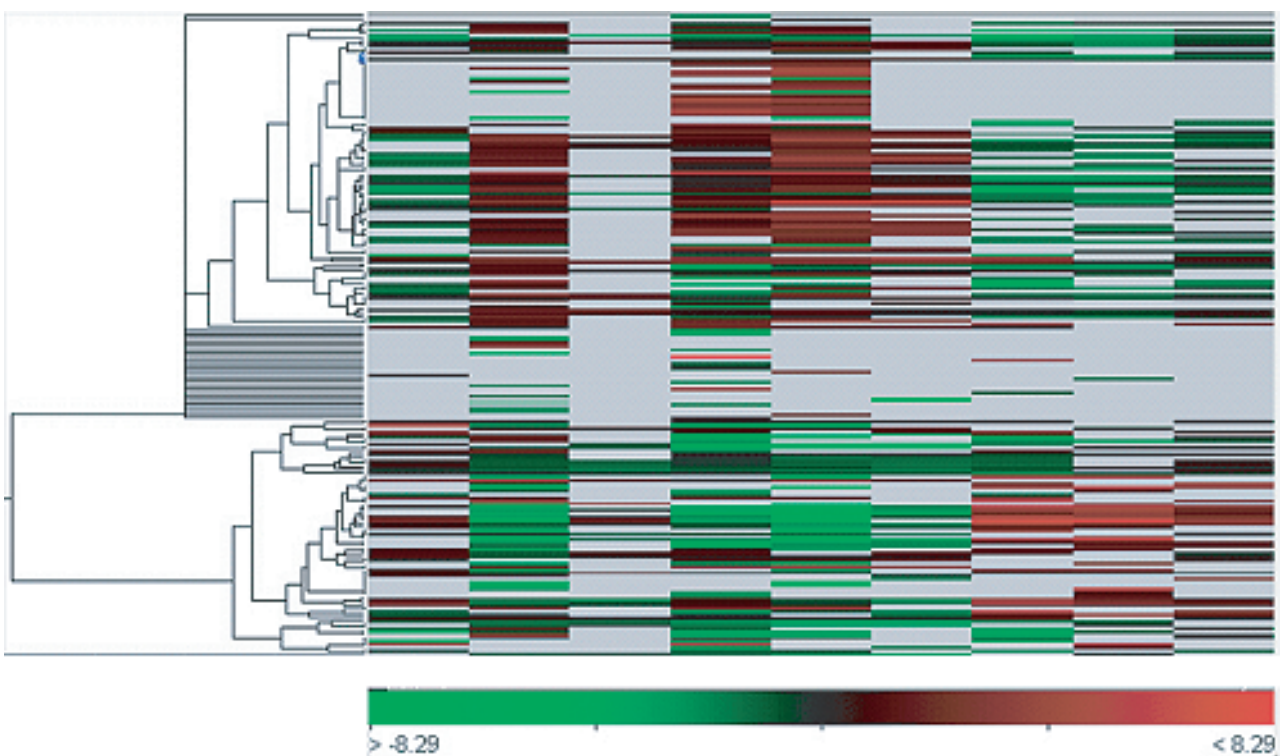

(a)

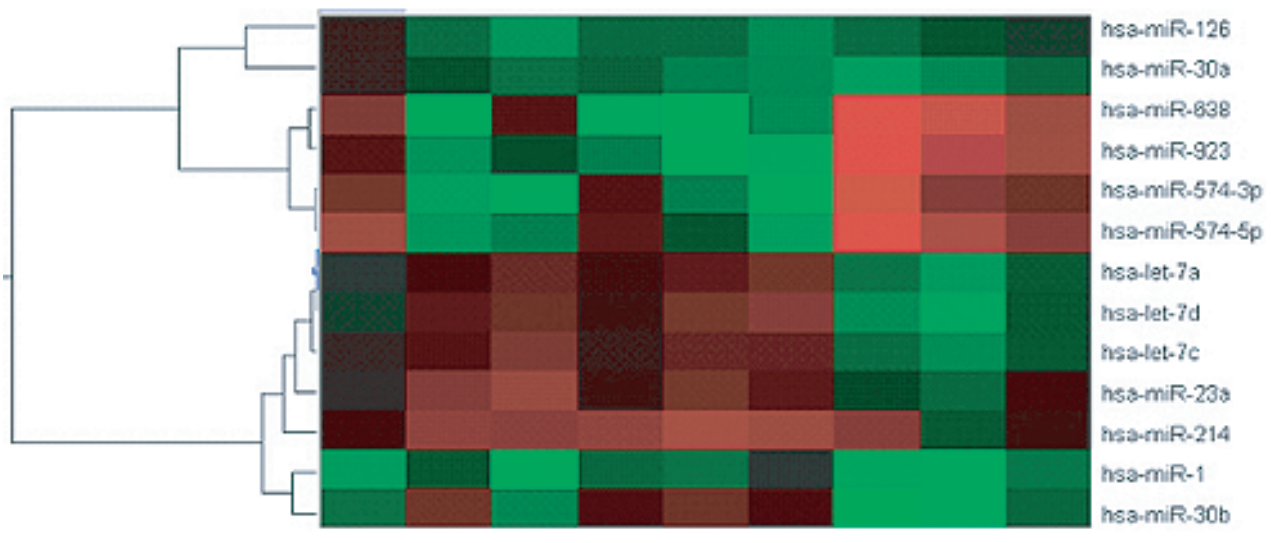

(b)

Fig. 2. Hierarchical clustering analysis of the $\log _{2}$ value of differentially expressed miRNAs in infarcted tissue and foetal hearts compared to healthy adult hearts. The statistical analysis and hierarchical clustering was performed using Acuity 4.0 analytical software. The results are displayed in a heat map. The legend on the right indicates the miRNA shown in the corresponding row, all of which are human specific. The bar code on the bottom represents the colour scale of the $\log _{2}$ value. Each column represents data from a given microarray, indicated at the bottom of the heat map. a) Heat map of 196 miRNAs dysregulated in at least one microarray; b) Heat map of 13 miRNAs dysregulated in all tested groups. Legend: Red, up-regulation; green, down-regulation; black, no change; 7d, myocardial infarcts up to 7 days old; $4 \mathrm{w}$, myocardial infarction more than 4 weeks old; F, foetal hearts.

and $m i R-575$, which showed dysregulated expression in MI. Most of the predicted binding sites are conserved across species and half of the genes possess more than one potential binding site for miRNA. All of the genes are believed to be involved in the pathogenesis of cardiovascular diseases or cardiogenesis. Gene functional classification using the DAVID program defined two groups of genes: a protein kinase group and their receptors and a transcription factor group, containing 10 and 5 predicted genes, respectively. Twenty-two genes were not clustered. The results are summarized in Table 3 . 
Table 2

Results of heart tissue miRNA expression profiling

\begin{tabular}{ll}
\hline & miRNAs \\
\hline miRNAs rep- & let-7a, let-7b, let-7c, let-7d, let-7e, let-7f, let-7g, let-7i, miR-1, miR-100, miR-103, miR-106a, miR-106b, miR-107, \\
resented in all & miR-125a-5p, miR-125b, miR-126, miR-127-3p, miR-128, miR-130a, miR-130b, miR-133a, miR-133b, miR-139-5p, \\
15 tested tiss- & miR-140-3p, miR-143, miR-145, miR-149*, miR-150, miR-151-3p, miR-151-5p, miR-152, miR-155, miR-16, miR-17, \\
ues & miR-181a, miR-181b, miR-185, miR-191, miR-191*, miR-193a-5p, miR-195, miR-197, miR-199a-3p, miR-199a-5p, \\
& miR-20a, miR-21, miR-210, miR-214, miR-22, miR-22*, miR-221, miR-222, miR-23a, miR-24, miR-24-2*, miR-26a, \\
& miR-26b, miR-27a, miR-27b, miR-30a, miR-30b, miR-30c, miR-30d, miR-320, miR-324-5p, miR-328, miR-331-5p, miR- \\
& 342-3p, miR-34a, miR-361-5p, miR-378, miR-378*, miR-422a, miR-423-5p, miR-451, miR-455-3p, miR-484, miR-486- \\
& 5p, miR-494, miR-499-5p, miR-532-5p, miR-574-3p, miR-574-5p, miR-575, miR-584, miR-628-3p, miR-638, miR-652, \\
& miR-663, miR-671-5p, miR-768-3p, miR-768-5p, miR-801, miR-923, miR-92a, miR-92b, miR-93, miR-933, miR-99a, \\
& miR-99b \\
miRNAs abs- & miR-15a*, miR-202*, miR-20a*, miR-220b, miR-26a-2*, miR-26b*, miR-298, miR-302a*, miR-32, miR-338-3p, miR- \\
ent from all & 33b, miR-369-3p, , miR-488, miR-488*, miR-508-3p, miR-509-3-5p, miR-520e, miR-520f, miR-520g, miR-521, miR- \\
15 tested tiss- & 523, miR-525-3p, miR-526b, miR-541, miR-542-3p, miR-545, miR-545*, miR-548a-3p, miR-548b-3p, miR-548c-3p, \\
ues & miR-548c-5p, miR-548d-3p, miR-548d-5p, miR-552, miR-558, miR-598*, miR-590-3p, miR-590-5p, miR-591, miR-592, \\
& miR-593 miR-593*, miR-597, miR-599, miR-600, miR-603, miR-604, miR-606, miR-607, miR-613, miR-614, miR-619, \\
& miR-620, miR-621, miR-626, miR-655, miR-656, miR-657, miR-661, miR-662, miR-708*, miR-7-2*, miR-744*, miR- \\
& 767-3p, miR-767-5p, miR-873, miR-875-3p, miR-875-5p, miR-876-3p, miR-829b, miR-920, miR-93*, miR-935, miR-941, \\
\hline & miR-96, miR-96*
\end{tabular}

Our analysis identified 101 miRNAs that were detected in all 15 tested heart tissues, and 77 miRNAs that were below the detection signal. Among miRNAs detected in all tested tissues, 53 (bold face miRNAs) appeared to be differentially expressed among tested groups.
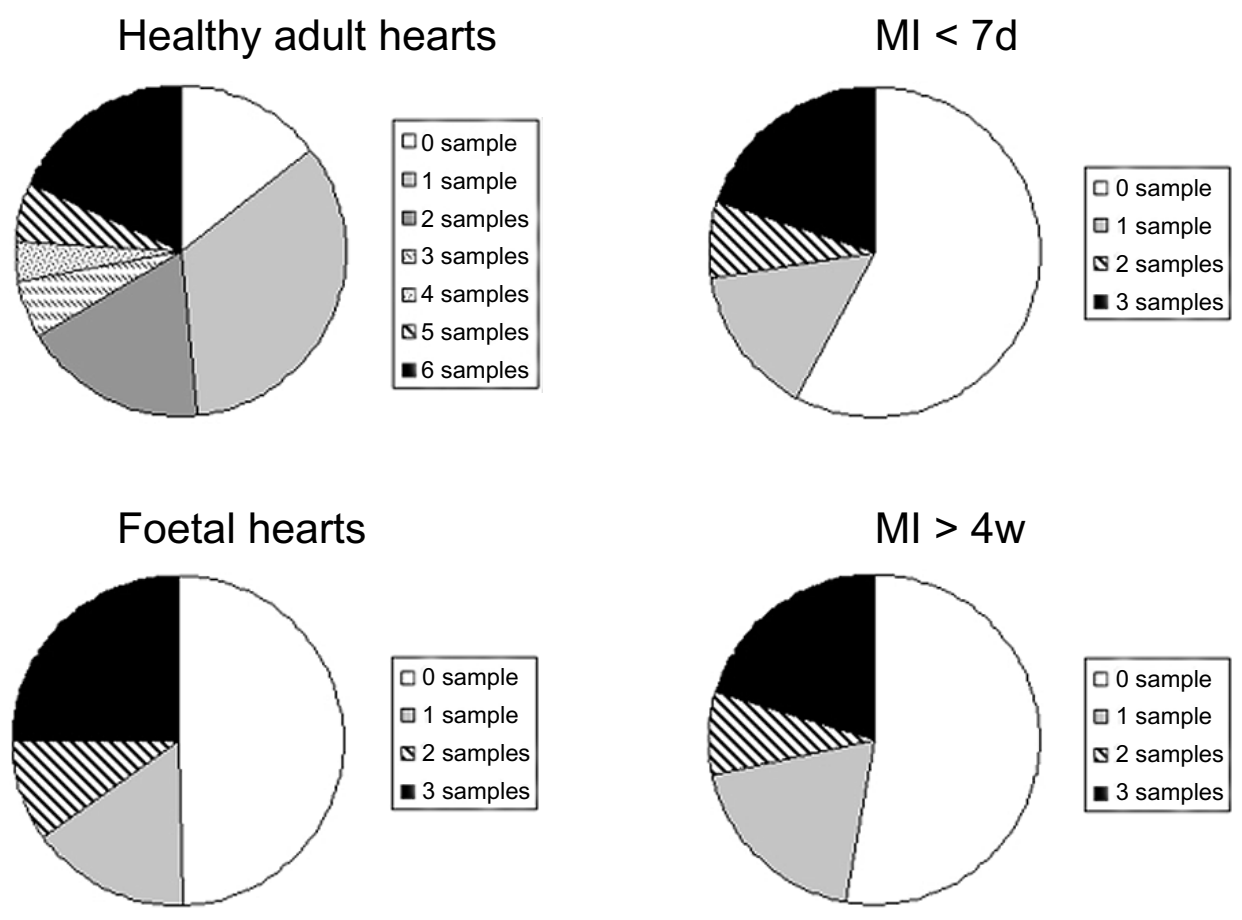

Fig. 3. The frequencies of miRNAs expressed in MI, foetal hearts, and healthy adult hearts. These miRNAs were defined as "detectable transcripts", but had either similar expression intensity or were absent from other samples and were therefore not treated as dysregulated. Legend: MI $<7$ d, myocardial infarction up to 7 days old; MI $>4 \mathrm{w}$, myocardial infarction more than 4 weeks old.

\section{2. $q R T-P C R$ and statistical analysis}

Microarray validation was performed using 7 randomly selected miRNAs from 93 dysregulated miR-
NAs as defined by microarray expression analysis.

We first tested 2 miRNAs among miRNAs previously reported to be dysregulated in hypoxia in cancer. Of these, 17 miRNAs showed a similar expression pattern 
Table 3

Predicted target genes for 5 dysregulated miRNAs in MI

\begin{tabular}{|c|c|c|c|}
\hline \multirow{2}{*}{ miRNA } & \multicolumn{2}{|r|}{ Predicted targets } & \multirow{2}{*}{$\begin{array}{l}\text { Number of } \\
\text { binding sites }\end{array}$} \\
\hline & Gene symbol & Gene name & \\
\hline \multirow[t]{17}{*}{ miR-1231 } & PRKCI $^{1}$ & Protein kinase $\mathrm{C}$, iota & 1 \\
\hline & SMAD6 $^{2}$ & SMAD family member 6 & 1 \\
\hline & KLF15 2 & Krupell-like factor 15 & 2 \\
\hline & CACNA2D2 & Calcium channel, voltage-dependent $\alpha 2 / \delta 2$ & 3 \\
\hline & KCNA1 & Potassium voltage-gated channel & 2 \\
\hline & GNAI2 & G protein & 1 \\
\hline & NOTCH2 & Notch homolog 2 & 2 \\
\hline & MYH10 & Myosin, heavy chain 10 & 1 \\
\hline & HDGF & Hepatoma-derived growth factor & 1 \\
\hline & FZD4 & Frizzled homolog 4 & 1 \\
\hline & PIK3R1 & Phosphoinositide-3-kinase & 2 \\
\hline & CREPBBP & CREB binding protein & 2 \\
\hline & MAP2K $4^{1}$ & Mitogen-activated protein kinase kinase 4 & 1 \\
\hline & BCL2 & B-cell CLL/lymphoma 2 & 1 \\
\hline & TEAD $1^{2}$ & TEA domain family member 1 & 1 \\
\hline & MBNL1 & Muscleblind-like & 1 \\
\hline & IGFBP5 & Insulin-like growth factor binding protein 5 & 1 \\
\hline \multirow[t]{2}{*}{$\operatorname{miR}-572$} & NCAM1 & Neural cell adhesion molecule 1 & 1 \\
\hline & ADRBK $^{1}$ & Adrenergic beta receptor kinase 1 & 1 \\
\hline \multirow[t]{12}{*}{$\operatorname{miR}-575$} & GCLC & Glutamate-cysteine lygase & 2 \\
\hline & PURA & Purine-rich element binding protein A & 1 \\
\hline & ADIPOR2 & Adiponectin receptor 2 & 2 \\
\hline & GATA4 & GATA 4 binding protein 4 & 1 \\
\hline & $\mathrm{DDR} 1^{1}$ & Discoidin receptor tyrosine kinase 1 & 2 \\
\hline & PRKCE $^{1}$ & Protein kinase $\mathrm{C}, \varepsilon$ & 1 \\
\hline & SEMA3F & Semaphorin & 1 \\
\hline & $\mathrm{HIF}_{1 \mathrm{AN}}{ }^{2}$ & Hypoxia inducibile factor 1 & 1 \\
\hline & KCNJ11 & Potassium channel, subfamily J, member 11 & 2 \\
\hline & $\mathrm{TEF}^{2}$ & Thyrotrophic embryonic factor & 1 \\
\hline & IGFBP3 & Insulin-like growth factor binding protein 3 & 1 \\
\hline & $\mathrm{CNP}$ & Cyclic nucleotide phosphodiesterase & 2 \\
\hline miR-933 & BDNF & Brain derived neurotrophic factor & 1 \\
\hline \multirow[t]{11}{*}{$\operatorname{miR}-574-3 p$} & $\mathrm{SRF}^{2}$ & Serum response factor & 2 \\
\hline & ATP2A2 & Calcium ATPase, endoplasmic reticulum & 2 \\
\hline & $\mathrm{MEF} 2 \mathrm{D} / 2 \mathrm{~A}^{2}$ & Myocyte enhacer factor $2 \mathrm{D} / 2 \mathrm{~A}$ & $2 / 1$ \\
\hline & EGR $^{2}$ & Early growth response 3 & 1 \\
\hline & $\mathrm{NRF}^{2}$ & Nuclear respiratory factor & 1 \\
\hline & GNAQ & Guanine nucleotide binding (G protein) & 1 \\
\hline & IL6 & Interleukin 6 & 1 \\
\hline & RGS14 & Regulator of $\mathrm{G}$ protein signaling & 1 \\
\hline & XIAP & $\mathrm{X}$-linked inhibitor of apoptosis & 1 \\
\hline & ADRA1B & Adrenergic $\alpha 1 \mathrm{~B}$ receptor 1 & 1 \\
\hline & TGFB2 & Transforming growth factor $\beta 2$ & 1 \\
\hline
\end{tabular}

Gene functional classification using the DAVID program clustered 15 genes in two groups, 22 genes were not grouped. Legend: ${ }^{1}$ protein kinase group and their receptors; ${ }^{2}$ transcription factor group.

in MI. These are: $m i R-23 a, m i R-24, m i R-195, m i R-$ 210, miR-214, miR-572, miR-15b, miR-26b, miR-30b, miR-186, let-7a, let-7c, let-7d, let-7e, let-7f and let$7 g$. In the context of ischemic stress, we performed qRT-PCR validation on $m i R-210$ and $m i R-186$. In addition, we validated the expression of $m i R-150$, which has the same mRNA target as $m i R-186$. We further tested $m i R-451$, which is believed to be erythroid specific miRNA. Finally, muscle-specific $m i R-1, m i R-133 a$ and $m i R-133 b$ were of special interest. The results are summarized in Fig. 4.

qRT-PCR results confirmed $m i R-210, m i R-451, m i R$ 150 and $m i R-186$ up-regulation (Mann-Whitney test, $p<0.000$ for $m i R-210$ and $m i R-451, p<0.01$ for $m i R$ 150 and $m i R-186$, SPSSv16.0), and $m i R-1$ and $m i R$ $133 a / b$ down-regulation in MI up to 7 days old when compared to healthy adult hearts.

There was no correlation of tested miRNA expres- 

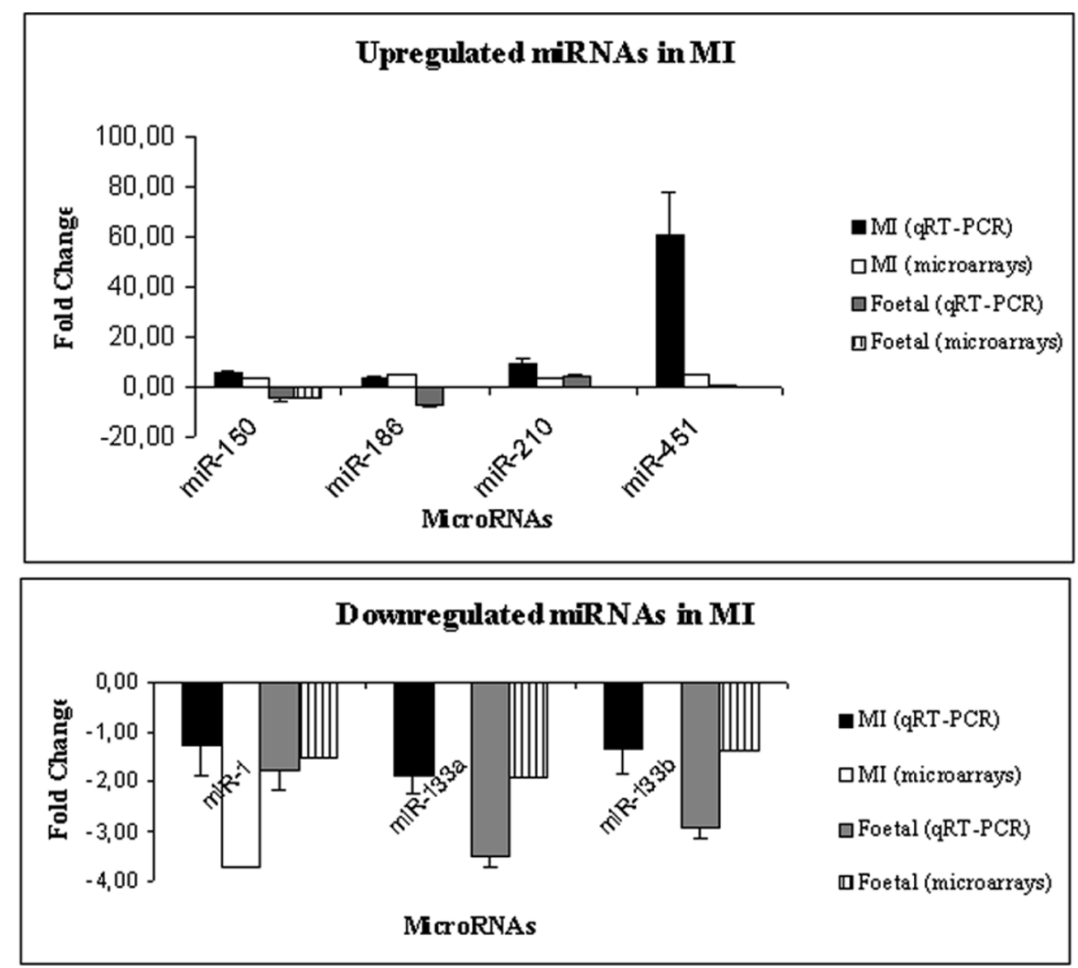

Fig. 4. Comparison of miRNA expression fold change in human myocardial infarction and foetal hearts compared to healthy adult hearts. Statistical analysis was performed using the Mann-Whitney test with a cut of point at $p<0.05$.

sion with the presence of hypertension, diabetes or reperfusion treatment.

qRT-PCR analysis performed on foetal hearts confirmed the down-regulation observed in microarray analysis of all tested miRNAs: $m i R-1, m i R-133 a / b$ (Mann-Whitney test, $p<0.05$, SPSSv16.0), and miR150 , and in addition for $m i R-186$. Further, similar to MI, miR-210 was up-regulated (Mann-Whitney test, $p<0.01$, SPSSv16.0) and according to microarray results, $m i R-451$ showed no change in expression in foetal when compared to healthy adult hearts.

\section{Discussion}

In this study, microRNA microarray analysis was performed on patients with myocardial infarction (MI) and foetal hearts compared to healthy adult hearts, in which 93 miRNAs showed dysregulation in MI or foetal hearts when compared to healthy adults. Searching across HMDD, PubMed and miRBase revealed that several studies have been performed using miRNA microarray analysis to define dysregulated miRNAs in various forms of cardiovascular disease [9-22,28].
Compared to previous research, our study identified 10 miRNAs of 93 treated as dysregulated, which have no record in HMDD or PubMed related to cardiovascular disease, and 5 miRNAs that have been previously reported in cell line experiments or animal models, but not on human samples of diseased hearts [9-22]. For 5 miRNAs, not previously related to heart disease, which were dysregulated in MI, we predicted 37 putative targets involved in cardiogenesis or cardiovascular disease. These are (i) protein kinase or their receptors, and (ii) transcription factors, some of which are already known to regulate or be regulated by miRNAs (MEF, SRF) [3,5]. It thus seems important to update microarrays with the latest version of the Sanger miRBase database, which contains $100 \%$ of experimentally verified miRNA sequences, since 17 miRNAs were detected only by such microarrays [10,11,13,18,21]. Frequency analysis of miRNA detected in the analyzed heart samples suggests that approximately $50 \%$ of the 719 miRNAs tested are expressed in human heart tissue. In addition, we identified 101 miRNAs that were detected in all 15 tested heart tissues, of which only 53 appeared to be differentially expressed between tested groups. That is about half of miRNAs constitutively 
expressed in adult or foetal hearts, which may be involved in response to ischemic stress. Finally, using the above-described platform, 77 miRNAs were below the detection signal.

Of 93 differentially expressed miRNAs, only 13 showed up- or down-regulation in all tested groups, which suggests a small amount of overlapping differentially expressed miRNA transcripts in human MI and foetal hearts. Statistical analysis revealed $57 \mathrm{miR}$ NAs that appeared to be confidently dysregulated between foetuses and up to 7-day or more than 4-week old MI. Unsupervised hierarchical clustering was performed and the resulting heat maps defined some similar expression patterns in more than 4-week old MI and foetal hearts, thus further supporting the concept of similarities of cardiac transcriptome between foetal and diseased hearts or, in other words, the concept of the "reactivation" of the foetal miRNA program in cardiovascular diseases [15]. Another similarity in miRNA expression was miRNAs previously reported to be dysregulated in hypoxia in cancer, 17 of which have a similar expression pattern in MI, and they are defined as hypoxia-regulated miRNAs (HRMs) [29,30]. Hypoxia is a feature of many diseases, including pulmonary hypertension, chronic obstructive pulmonary disease, sepsis, myocardial ischemia and cancer. The series includes articles related to new areas for hypoxiainducibile factors (HIF), which are key transcriptional regulators in the complex molecular mechanisms of response to hypoxia. They orchestrate the expression of a wide variety of genes that affect metabolism, angiogenesis, cell survival and oxygen delivery and, in addition, miRNA expression, thought to be critical for adaptation to low oxygen [29-31]. Myocardial ischemia is the most common cause of cardiac hypoxia in clinical medicine, and occurs when oxygen delivery cannot meet myocardial metabolic requirements in the heart. Among the transcriptional regulators activated are members of the HIF transcription factor family. HIF proteins are activated by oxidative stress and are increased in the peri-infarcted area after MI in rats and humans, and in remote areas from the MI. Although it has been recognized for a decade that HIF transcription factors are activated by environmental stress, the exact role of HIF members in cardiac ischemic injury remains unknown [32].

In our study some HRMs were used for microarray validation using qRT-PCR. All validations confirmed the microarray results and, moreover, all miRNAs tested, except muscle-specific miRNAs $m i R-1$ and $m i R$ $133 a / b$, showed significant up-regulation in MI. In ad- dition, using qRT-PCR, all of the microarray results were confirmed in foetal hearts, except $m i R-210$ and $m i R-186$, which showed no difference in expression on the basis of microarray analysis, but were dysregulated when expression was analyzed using qRT-PCT. This may be due to the more sensitive approach used for microarray validation.

Several targets have previously been proposed and in vitro or in vivo tested for validated miRNAs. Among them, $m i R-210$ is believed to regulate ephrin-A3 [33] and E2F3 [34]; $m i R-150$ and $m i R-186$ have the same target $\mathrm{P} 2 \mathrm{X} 7$ receptor [35] and showed similar expression patterns in human MI and in foetal hearts; $m i R-451$ has been shown to regulate MIF production [36] and GATA2 expression [37]. Finally, several targets have been shown for muscle-specific miR-1 and miR-133: Rheb, RasGAP, Cdk9, fibronectin, HSP60, HSP70, KCNJ2, GJA1 for $m i R-1$, and RhoA, NELF, Cdc42, $H E R G$, Caspase-9 for $m i R-133$, and KCNE1, KCNQ1, $H C N 2 / H C N 4$ for $m i R-1$ and $m i R-133$ [8,28]. All these genes are already known to be involved in heart development, physiology or pathology. In addition, target prediction for 5 miRNAs, which were dysregulated in MI and not previously related to cardiovascular diseases, identified genes involved in a variety of physiological and pathological processes in the setting of diseased hearts. In silico searches revealed a highly complex spectrum of candidate targets, including genes involved in proliferation, apoptosis, DNA repair, chromatin remodelling, metabolism and migration. Most of the processes are induced by and/or included in response to hypoxia [32].

However, at the time of writing, some additional miRNAs were shown, using animal models, to be involved in ischemia and were also dysregulated in our study. These miRNAs are miR-320 targeting HSP20 [19], $m i R-1, m i R-24$ and $m i R-21$ possibly through up-regulating eNOS, HSP70 and HSF-1 [38, 39 ], and $m i R-92 a$ targeting several pro-angiogenic proteins, including integrin subunit alpha5 [40].

In conclusion, our results revealed some miRNA patterns similar to foetal hearts, supporting the concept of the reactivation of the foetal miRNA program in cardiovascular diseases, and to hypoxia in cancer, indicating similar miRNA expression patterns in cardiac ischemia. Finally, our results showed the involvement of novel miRNAs in MI in humans. Of the 15 miRNAs not previously shown to be related to cardiovascular diseases in humans, 5 had previously been shown to be dysregulated only in animal models of diseased heart, and 10 had not yet been described in the setting of 
cardiovascular diseases. Our study of human miRNA expression in MI, foetal hearts and healthy adult hearts will therefore perhaps guide further studies on the contribution of miRNAs to heart disease pathogenesis.

\section{Acknowledgement}

The Slovenian Research Agency (ARRS) (Program P3-054) supported this work, which is a part of the $\mathrm{PhD}$ thesis of candidate Emanuela Boštjančič BSc of Microbiology.

\section{References}

[1] C. Zhang, MicroRNAs: role in cardiovascular biology and disease, Clin Sci (Lond) 114 (2008), 699-706.

[2] Z. Wang, X. Luo, Y. Lu and B. Yang, miRNAs at the heart of the matter, J Mol Med 86 (2008), 771-783.

[3] N. Liu, S. Bezprozvannaya, A.H. Williams, X. Qi, J.A. Richardson, R. Bassel-Duby and E.N. Olson, microRNA-133a regulates cardiomyocyte proliferation and suppresses smooth muscle gene expression in the heart, Genes Dev 22 (2008), 3242-3254.

[4] S.U. Morton, P.J. Scherz, K.R. Cordes, K.N. Ivey, D.Y. Stainier and D. Srivastava, microRNA-138 modulates cardiac patterning during embryonic development, Proc Natl Acad Sci U S A 105 (2008), 17830-17835.

[5] T.E. Callis, J.F. Chen and D.Z. Wang, MicroRNAs in skeletal and cardiac muscle development, DNA Cell Biol 26 (2007), 219-225.

[6] R.J. Perera and A. Ray, MicroRNAs in the search for understanding human diseases, BioDrugs 21 (2007), 97-104.

[7] M.V. Latronico, D. Catalucci and G. Condorelli, MicroRNA and cardiac pathologies, Physiol Genomics 34 (2008), 239242.

[8] M.V. Latronico, D. Catalucci and G. Condorelli, Emerging role of microRNAs in cardiovascular biology, Circ Res $\mathbf{1 0 1}$ (2007), 1225-1236.

[9] E. van Rooij, L.B. Sutherland, N. Liu, A.H. Williams, J. McAnally, R.D. Gerard, J.A. Richardson and E.N. Olson, A signature pattern of stress-responsive microRNAs that can evoke cardiac hypertrophy and heart failure, Proc Natl Acad Sci USA 103 (2006), 18255-18260.

[10] D. Sayed, C. Hong, I.-Y. Chen, J. Lypowy and M. Abdellatif, MicroRNAs play an essential role in the development of cardiac hypertrophy, Circ Res 100 (2007), 416-424.

[11] Y. Cheng, R. Ji, J. Yue, J. Yang, X. Liu, H. Chen, D.B. Dean and C. Zhang, MicroRNAs are aberrantly expressed in hypertrophic heart: do they play a role in cardiac hypertrophy? Am J Pathol 170 (2007), 1831-1840.

[12] M. Tatsuguchi, H.Y. Seok, T.E. Callis, J.M. Thomson, J.F. Chen, M. Newman, M. Rojas, S.M. Hammond and D.Z. Wang, Expression of microRNAs is dynamically regulated during cardiomyocyte hypertrophy, J Mol Cell Cardiol 42 (2007), 1137-1141.

[13] C. Sucharov, M.R. Bristow and J.D. Port, miRNA expression in the failing human heart: functional correlates, $\mathrm{J}$ Mol Cell Cardiol 45 (2008), 185-192.
[14] S. Ikeda, S.W. Kong, J. Lu, E. Bisping, H. Zhang, P.D. Allen, T.R. Golub, B. Pieske and W.T. Pu, Altered microRNA expression in human heart disease, Physiol Genomics 31 (2007), 367-373.

[15] T. Thum, P. Galuppo, C. Wolf, J. Fiedler, S. Kneitz, L.W. van Laake, P.A. Doevendans, C.L. Mummery, J. Borlak, A. Haverich, C. Gross, S. Engelhardt, G. Ertl and J. Bauersachs, MicroRNAs in the human heart: a clue to fetal gene reprogramming in heart failure, Circulation 116 (2007), 258-267.

[16] S.J. Matkovich, D.J. Van Booven, K.A. Youker, G. TorreAmione, A. Diwan, W.H. Eschenbacher, L.E. Dorn, M.A. Watson, K.B. Margulies and G.W. Dorn $2^{\text {nd }}$, Reciprocal regulation of myocardial microRNAs and messenger RNA in human cardiomyopathy and reversal of the microRNA signature by biomechanical support, Circulation 119 (2009), 1263-1271.

[17] P.A. Costa Martins, M. Bourajjaj, M. Gladka, M. Kortland, R.J. van Oort, Y.M. Pinto, J.D. Molkentin and L.J. De Windt, Conditional dicer gene deletion in the postnatal myocardium provokes spontaneous cardiac remodeling, Circulation 118 (2008), 1567-1576.

[18] E. van Rooij, L.B. Sutherland, J.E. Thatcher, J.M. DiMaio, R.H. Naseem, W.S. Marshall, J.A. Hill and E.N. Olson, Dysregulation of microRNAs after myocardial infarction reveals a role of miR-29 in cardiac fibrosis, Proc Natl Acad Sci USA 105 (2008), 13027-13032.

[19] X.-P. Ren, J. Wu, X. Wang, M.A. Sartor, J. Qian, K. Jones, P. Nicolaou, T.J. Pritchard and G.-C. Fan, MicroRNA-320 is involved in the regulation of cardiac ischemia/reperfusion injury by targeting heat-shock protein 20, Mol Cardiol 119 (2009), 2357-2366.

[20] S. Roy, S. Khanna, S.R. Hussain, S. Biswas, A. Azad, C. Rink, S. Gnyawali, S. Shilo, G.J. Nuovo and C.K. Sen, MicroRNA expression in response to murine myocardial infarction: miR21 regulates fibroblast metalloprotease- 2 via phosphatase and tensin homologue, Cardiovasc Res 82 (2009), 21-29.

[21] Z. Niu, D. Iyer, S.J. Conway, J.F. Martin, K. Ivey, D. Srivastava, A. Nordheim and R.J. Schwartz, Serum response factor orchestrates nascent sarcomerogenesis and silences the biomineralization gene program in the heart, Proc Natl Acad Sci USA 105 (2008), 17824-17829.

[22] J. Wang, R. Xu, F. Lin, S. Zhang, G. Zhang, S. Hu and Z. Zheng, MicroRNA: novel regulators involved in the remodeling and reverse remodeling of the heart, Cardiology 113 (2009), 81-88.

[23] T.S. Davidson, C.D. Johnson and B.F. Andruss, Analyzing micro-RNA expression using microarrays, Methods Enzymol 411 (2006), 14-34.

[24] S. Griffiths-Jones, H.K. Saini, S. van Dongen and A.J. Enright, miRBase: tools for microRNA genomics, Nucleic Acids Res 36 (2008), D154-D158.

[25] M. Lu, Q. Zhang, M. Deng, J. Miao, Y. Guo, W. Gao and Q. Cui, An analysis of human microRNA and disease associations, PLOSONE 3 (2008), e 3420.

[26] I. Ioshikhes, S. Roy and C.K. Sen, Algorithms for mapping of mRNA targets for microRNA, DNA Cell Biol 26 (2007), 265-272.

[27] D.W. Huang, B.T. Sherman and R.A. Lempicki, Systematic and integrative analysis of large gene lists using DAVID bioinformatics resources, Nat Protoc 4 (2009), 44-57.

[28] V. Divakaran and D. L. Mann, The emerging role of microRNAs in cardiac remodeling and heart failure, Circ Res $\mathbf{1 0 3}$ (2008), 1072-1083.

[29] R. Kulshreshtha, R.V. Davuluri, G.A. Calin and M. Ivan, microRNA component of the hypoxic response, Cell Death Dif- 
fer 15 (2008), 667-671.

[30] R. Kulshreshtha, M. Ferracin, M. Negrini, G.A. Calin, R.V. Davuluri and M. Ivan, Regulation of microRNA expression: the hypoxic component, Cell Cycle 6 (2007), 1426-1431.

[31] N.S. Chandel and M.C. Simon, Hypoxia-inducible factor: roles in development, physiology, and disease, Cell Death Differ 15 (2008), 619-620.

[32] R.V. Shohet and J.A. Garcia, Keeping the engine primed: HIF factors as key regulators of cardiac metabolism and angiogenesis during ischemia, $J$ Mol Med 85 (2007), 1309-1315.

[33] P. Fasanaro, Y. D’Alessandra, V. Di Stefano, R. Melchionna, S. Romani, G. Pompilio, M.C. Capogrossi and F. Martelli, MicroRNA-210 modulates endothelial cell response to hypoxia and inhibits the receptor tyrosine kinase ligand Ephrin-A3, J Biol Chem 283 (2008), 15878-15883.

[34] A. Giannakakis, R. Sandaltzopoulos, J. Greshock, S. Liang, J. Huang, K. Hasegawa, C. Li, A. O’Brien-Jenkins, D. Katsaros, B.L. Weber, C. Simon, G. Coukos and L. Zhang, miR-210 links hypoxia with cell cycle regulation and is deleted in human epithelial ovarian cancer, Cancer Biol Ther 7 (2008), 255-264.

[35] L. Zhou, X. Qi, J.A. Potashkin, F.W. Abdul-Karim and G.I. Gorodeski, MicroRNAs miR-186 and miR-150 down-regulate expression of the pro-apoptotic purinergic $\mathrm{P} 2 \mathrm{X} 7$ receptor by activation of instability sites at the 3'-untranslated region of the gene that decrease steady-state levels of the transcript, $J$
Biol Chem 283 (2008), 28274-28286.

[36] E. Bandres, N. Bitarte, F. Arias, J. Agorreta, P. Fortes, X. Agirre, R. Zarate, J.A. Diaz-Gonzalez, N. Ramirez, J.J. Sola, P. Jimenez, J. Rodriguez and J. Garcia-Foncillas. microRNA-451 regulates macrophage migration inhibitory factor production and proliferation of gastrointestinal cancer cells, Clin Cancer Res 15 (2009), 2281-2290.

[37] L. Pase, J.E. Layton, W.P. Kloosterman, D. Carradice, P.M. Waterhouse and G.J. Lieschke, miR-451 regulates zebrafish erythroid maturation in vivo via its target gata2. Blood $\mathbf{1 1 3}$ (2009), 1794-1804.

[38] C. Yin, X. Wang and R.C. Kukreja, Endogenous microRNAs induced by heat-shock reduce myocardial infarction following ischemia-reperfusion in mice, FEBS Letters 582 (2008), 41374142.

[39] C. Yin, F.N. Salloum and R.C. Kukreja, A novel role of microRNA in late preconditioning: Upregulation of endothelial nitric oxide synthase and heat shock protein 70, Circ Res 104 (2009), 572-575.

[40] A. Bonauer, G. Carmona, M. Iwasaki, M. Mione, M. Koyanagi, A. Fischer, J. Burchfield, H. Fox, C. Doebele, K. Ohtani, E. Chavakis, M. Potente, M. Tjwa, C. Urbich, A.S. Zeiher and S. Dimmeler, MicroRNA-92a controls angiogenesis and functional recovery of ischemic tissue in mice, Science $\mathbf{3 2 4}$ (2009), 1710-1713. 


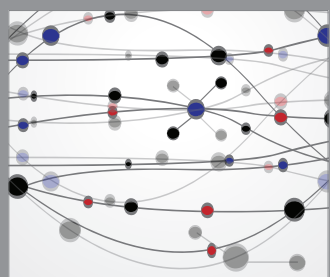

The Scientific World Journal
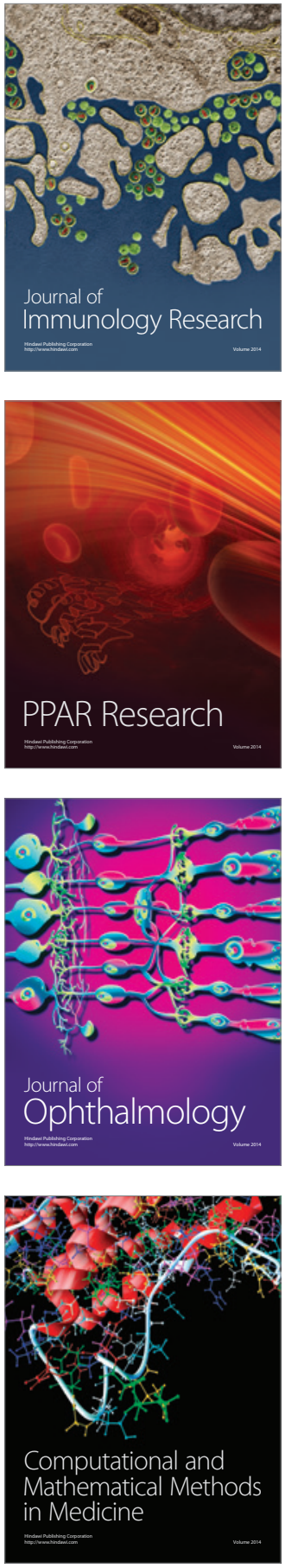

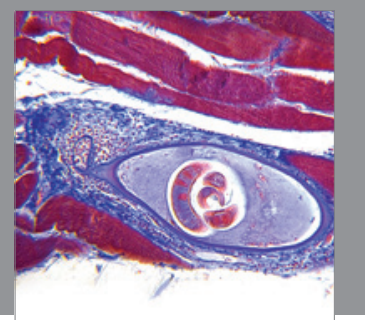

Gastroenterology

Research and Practice
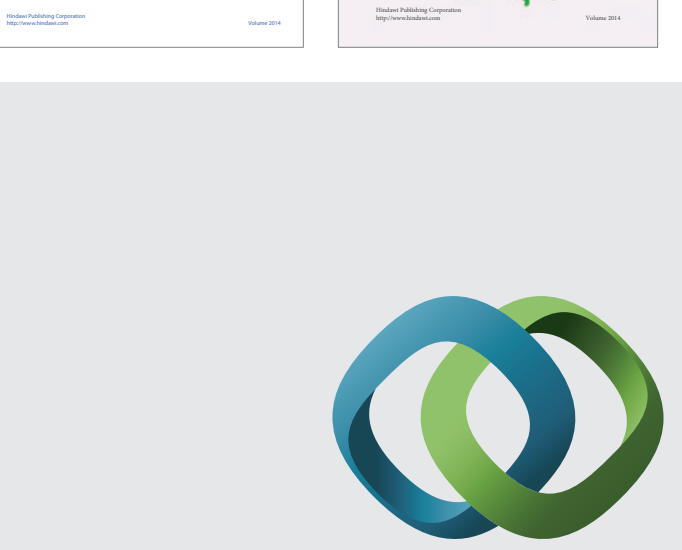

\section{Hindawi}

Submit your manuscripts at

http://www.hindawi.com
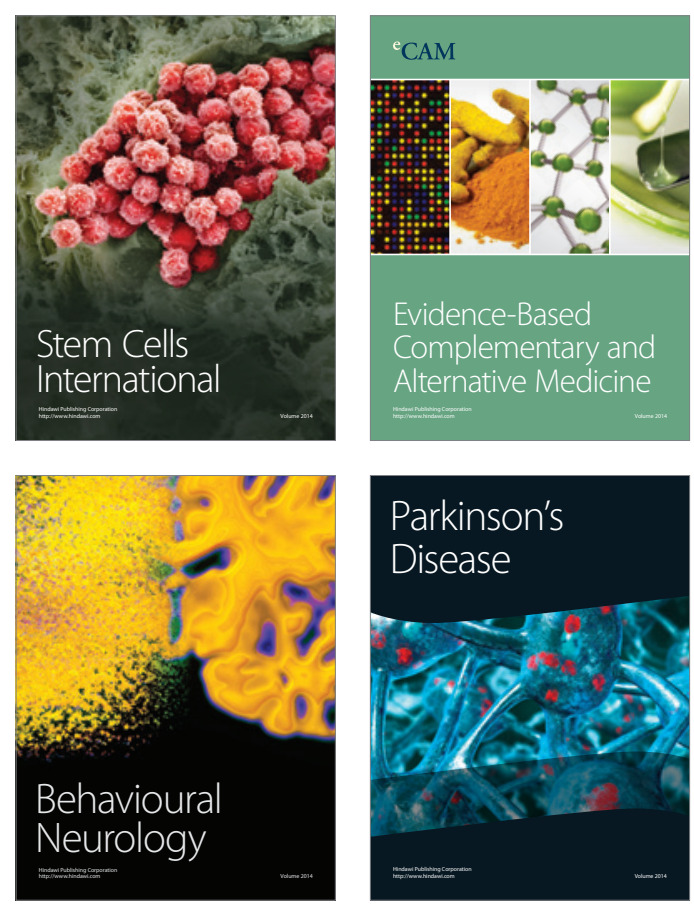

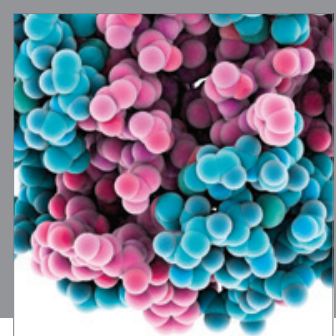

Journal of
Diabetes Research

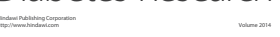

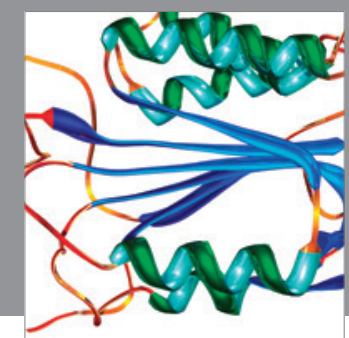

Disease Markers
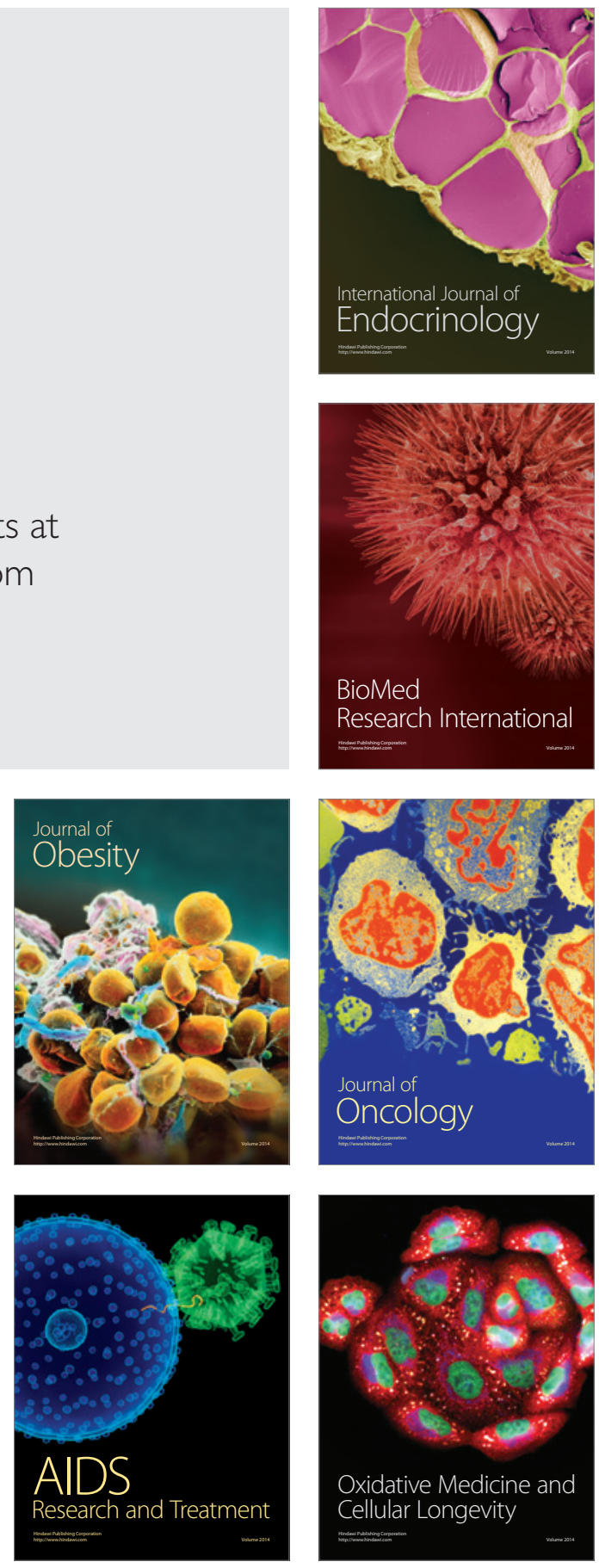